\title{
Relação Sintaxe-Semântica: uso e freqüência das principais estruturas dos verbos psicológicos ${ }^{1}$
}

Rapports entre la Syntaxe et la Sémantique: l'usage et la fréquence des principales structures des verbes psychologiques

\section{Evelyne Dogliani} Universidade Federal de Minas Gerais - UFMG

Résumé

Cet article présente une analyse des verbes psychologiques, basée sur des données d'usage. On y identifie les principales propriétés syntaxiques et l'on constate une relation entre structures morphologiques, sintaxiques, traits sémantiques et la perspective du discours. Cela nous permet de réfléchir à propos de l'organisation du lexique mental.

Mots-clés

Verbes psychologiques, Propriétés syntaxiques, Usage.

\section{Resumo}

Este artigo apresenta uma análise dos verbos psicológicos baseada em dados de uso. Identificam-se as principais propriedades sintáticas dos verbos e constata-se uma relação entre estruturas morfológicas, sintáticas, traços semânticos e perspectiva do discurso, o que enseja uma reflexão sobre a organização do léxico mental.

Palavras chave

Verbos psicológicos, Propriedades sintáticas, Uso. 


\section{Introdução}

$\mathrm{E}$ ste artigo resume uma análise do uso dos verbos psicológicos ergativocausativos. Apresentam-se evidências de que a propriedade de ergativização, que a literatura relevante atribui a esse subgrupo de verbos, é variável quanto à possibilidade de ocorrência e quanto ao tipo de estrutura morfológica através da qual se realiza. Isto é, sustenta-se que determinadas realizações desses verbos com operadores como ser, ficar constituem realizações alternativas semanticamente equivalentes à propriedade de ergativização propriamente dita. Constata-se, além disso, que as diferentes realizações morfológicas associam-se à perspectiva do enunciado, o que destaca a relevância da consideração de fatores semântico-discursivos para a compreensão do comportamento desses verbos.

\section{Descrição do objeto de estudo}

Os verbos que expressam sentimentos e emoções foram alvo do interesse de vários estudiosos devido à singularidade de sua estrutura argumental, entre outros fatores. Caracterizando-se por exibir um argumento com a função semântica de experienciador, ${ }^{2}$ um largo grupo desse tipo de verbo estrutura-se com o argumento experienciador tanto na função de sujeito quanto na de objeto sintático. De acordo com a literatura relevante, em que são comumente chamados psicoverbos, dividem-se em dois grupos, de acordo com a realização da propriedade de ergativização. O primeiro grupo é o dos inergativos, que, como indica o próprio rótulo, não admitem a propriedade de ergativização, como amar, conforme se ilustra em (1). O outro grupo é o dos ergativo-causativos, como preocupar, que, conforme se ilustra em (2), admitem a referida propriedade.

(1) Maria ama João.

(2) a) João preocupa Maria.

b) Maria (se) preocupa com João. 
Assim, os verbos inergativos, do tipo de amar e outros como desejar, temer, odiar só realizam o experienciador na posição de sujeito sintático. Os psicoverbos ergativo-causativos do tipo de preocupar e outros como amedrontar, assustar exibem o experienciador tanto na função de objeto sintático quanto na de sujeito sintático, quando realizam a propriedade de ergativização. ${ }^{3}$

A identificação desses dois grupos motiva diferentes explicações. Para os modelos teóricos que investem na sintaxe a identificação dos princípios da Gramática Universal, os diferentes comportamentos sintáticos dos verbos amar e preocupar, por exemplo, são explicados através da atribuição de diferentes estruturas de base a cada um deles: os que aceitam ergativização/causativização são aqueles que não têm sujeito profundo (amar tem sujeito profundo, preocupar não tem). Nesse quadro de análise, desencadeado por Perlmutter (1978) e seguido por Burzio (1986), Belletti \& Rizzi (1988), os fatos de sentido são levados em conta em um nível mais concreto da análise, de forma tal que os papéis temáticos não se caracterizam como primitivos da teoria. Além de gerar polêmica, por seu caráter ad hoc, segundo alguns, esse tipo de proposta deixa certos casos sem explicação: o verbo preocupar admite os dois tipos de ergativização; o verbo consolar, ao qual é atribuída a mesma estrutura argumental, só admite a ergativização com o pronome. Outros, como conquistar, embora descritos com o mesmo estrato inicial, não admitem nenhum tipo de ergativização.

Paralelamente, análises que atribuem à semântica o estatuto de componente autônomo (WHITAKER-FRANCHI, 1989; CANÇADO, 1995) propuseram que propriedades como as de ergativização são resultado da ordenação de papéis temáticos, tratados como primitivos do modelo e analisados ora como unidades discretas, ora como unidades contínuas. Mesmo nesse tipo de análise, que descreve mais adequadamente o funcionamento desses verbos, evidenciam-se comportamentos idiossincráticos: um verbo como conquistar integra a mesma rede temática de acalmar, mas, diferentemente desse último, não admite a ergativização. Tampouco se explica, nesse tipo de análise, por que alguns admitem a ergativização sem o pronome.

Uma observação do percurso histórico desses verbos (MADUREIRA, 2000, 2002) propôs que a variação observável pode ser resultante de mudança sintática implementada por Difusão Lexical. A variação da propriedade de ergativização seria decorrente de uma mudança anterior, qual seja, o processo de causativização ocorrido no português brasileiro, conforme Tarallo (1993) e 
Bittencourt (1995). Isto é, entre os verbos originalmente acusativos (como, por exemplo, aborrecer), o processo de causativização gerou estruturas ambíguas, o que dificultava a identificação do experienciador. Em Madureira (2000, 2002), propus que as estruturas pronominais emergiram no sistema da língua como recurso de desambiguação e que o uso dessas estruturas estendeu-se aos verbos originalmente não acusativos, como pasmar, nos quais o processo de causativização não gerou estruturas ambíguas. Assim, a análise diacrônica explica a emergência do pronome ergativo se para um subgrupo de verbos, como estrutura marcada. Essa marca foi progressivamente estendendo-se a outros verbos, assinalando a ocorrência do experienciador na função de sujeito sintático.

Essa análise detectou, ainda, uma predominância das realizações em que o experienciador se estrutura na função de sujeito. Outra peculiaridade observada no processo de ergativização foi a variação das realizações morfológicas dos verbos, que realizam estruturas semanticamente equivalentes, através de realizações perifrásticas. Isto é, observou-se que estruturas como Maria preocupa-se com João são freqüentemente substituídas, no caso de alguns verbos, por estruturas como Maria ficalé preocupada com João.

Na presente análise, agrupam-se as diferentes realizações morfológicas dos verbos, de acordo com a função sintática do experienciador, o que propicia a formação de dois grandes grupos, o das realizações em que o experienciador tem a função de sujeito (doravante estruturas ExpS) e o grupo no qual o experienciador se estrutura na posição de objeto (doravante estruturas ExpO). Observa-se, a seguir, o favorecimento que cada verbo exibe em relação à função sintática do experienciador e ao tipo de estrutura morfológica através da qual essa função se realiza. Finalmente, investiga-se a hipótese de que esses dois tipos de variação resultam de marcação lexical, fenômeno que, por sua vez, é imputado à interação de parâmetros semânticos e sintáticos. Nessa perspectiva da análise, demonstra-se que propriedades usadas como critério de distinção entre subgrupos de psicoverbos ergativo-causativos, como a passiva sintática (João foi humilhado por Pedro) a causativa encabeçada (Maria fez João humilhar Pedro), e a de pro-arbitrário (Humilharam João com aquela cena), analisadas em Cançado (1995, 1996), são raramente ilustradas por esses verbos e, por isso mesmo, de pouco alcance para distingui-los em subclasses. Sustenta-se, ainda, que essas propriedades são secundárias em relação a um outro grupo de propriedades, cuja frequiência de uso determina a configuração das primeiras. 


\section{O comportamento sintático dos verbos e sua história}

Madureira (2000) concluiu que a variação na propriedade de ergativização relaciona-se ao perfil histórico dos verbos, o que permitiu a seguinte subdivisão dos verbos psicológicos do português:

1) verbos que só admitem o experienciador na posição de sujeito (ex: temer, amar, desejar etc.);

2) verbos que admitem o experienciador na posição de sujeito ou na de objeto sintático da oração. Esse grupo compõe-se de verbos de distintas origens: a) acusativos não causativos (enojar, aborrecer) ou inacusativos (desesperar, pasmar) que se causativizaram; b) verbos originalmente causativos (confortar, animar) cujas estruturas reflexivas passaram a ter a possibilidade de leitura ergativa, por contaminação da leitura ergativa (pronominal e não pronominal) que os verbos do grupo a foram desenvolvendo;

3) verbos que só admitem o experienciador na posição de objeto (ex: humilhar, conquistar). Essa classe é a mais reduzida das três: compõe-se de verbos originalmente causativos que permanecem como tais.

A composição dos três grupos mostra que o segundo grupoé o mais produtivo. É nele que se abrigam os verbos que migram dos outros dois grupos: do primeiro, quando se causativizam; do terceiro, quando desenvolvem a propriedade de ergativização. Este artigo trata dos verbos dos grupos $2 \mathrm{e} 3$ (os ergativo-causativos) e tem por objetivo avaliar o comportamento desses verbos na perspectiva do falante. Tal objetivo pode justificar-se da seguinte maneira: ainda que dados adicionais confirmem a análise histórica proposta para esse grupo de verbos, a mesma há de ser ainda considerada insuficiente do ponto de vista do falante. Continua-se querendo saber que critérios guiam os falantes, quando os mesmos admitem (i) as duas construções ergativas para certos verbos; (ii) apenas uma das construções ergativas para outros e, por fim, (iii) nenhuma dessas construções para outros subgrupos de verbos. Busca-se, ainda, observar se existe relação entre a freqüência das construções ergativas e as outras propriedades sintáticas mencionadas em 1 .

Concebe-se que o percurso histórico de cada verbo tenha deixado pistas das quais o falante se serve para implementar certas construções para cada grupo de verbo e que essas pistas estejam delineadas na realização de alguns tipos de estruturas em detrimento de outras para cada tipo de verbo. Para tanto, foram observadas as estruturas sintático-semânticas nas quais os verbos psicológicos 
se realizam, analisando-se a distribuição do experienciador pelas funções sintáticas de sujeito e de objeto.

\section{Uma análise quantitativa dos verbos}

Os dados que orientam a presente análise foram extraídos de parte dos corpora que sustentaram a pesquisa relatada em Madureira (2000 e 2002). Isto é, selecionaram-se os dados do século XX (modalidades oral e escrita). Os dados da modalidade oral ilustram a fala de São Paulo e de Salvador (década de 70 projeto NURC) e de Belo Horizonte, com dados coletados na década de $80 .{ }^{4}$ Os dados da modalidade escrita foram extraídos de romances produzidos entre os anos 60 e 70. A primeira etapa da análise levou em conta 323 dados.

\subsection{O padrão sintático preferencial}

A tabela 1 apresenta a distribuição do experienciador (Exp) pelas funções sintáticas de sujeito (ExpS) e do objeto (ExpO), que se ilustram em (3) e (4), respectivamente.

(3) João (se) preocupa/fica preocupado com Maria.

(4) Maria preocupa João.

TABELA 1

Verbos por função sintática do experienciador

\begin{tabular}{ccc}
\hline $\begin{array}{c}\text { Função sintática do } \\
\text { experenciador }\end{array}$ & EXPS & EXPO \\
Dados por Exp & 208 & 115 \\
\% & 64.4 & 35.6 \\
\cline { 2 - 3 } TOTAL & \multicolumn{2}{c}{323} \\
\hline
\end{tabular}

A tabela 1 mostra que o conjunto dos verbos privilegia os enunciados em que o experienciador está estruturado na posição de sujeito sintático da oração (ExpS) e não na de objeto sintático (ExpO): 64.4\% das realizações dos verbos favorecem a perspectiva do experienciador, ilustrando estruturas do tipo de (3), enquanto $35.6 \%$ favorecem a perspectiva da causa, ilustrando estruturas do tipo de (4). 
Tendo em conta o comportamento idiossincrático de vários verbos, procedeu-se a uma observação do uso de cada um deles. Verbos com poucas ocorrências não permitem o estabelecimento de um perfil. Assim, para essa fase da análise, selecionaram-se os verbos que ocorreram sete vezes, no mínimo.

O subconjunto dos verbos com mais de sete ocorrências constitui um corpus de 299 dados. Quando se consideram os verbos mais freqüentes, observa-se um acirramento da diferença entre os dois tipos de estrutura, com favorecimento das estruturas ExpS. Dos 299 dados, 213 ocorrências, isto é, $71.2 \%$ favorecem a perspectiva do experienciador, realizando estruturas ExpS, conforme se pode ver na tabela 2 .

TABELA 2

Verbos por função sintática do experienciador (verbos mais freqüentes)

\begin{tabular}{ccc}
\hline Função Sintática do & EXPS & EXPO \\
Experenciador & & \\
Dados por Exp & 213 & 86 \\
\% & 71.2 & 28.8 \\
\cline { 2 - 3 } TOTAL & \multicolumn{2}{c}{299} \\
\hline
\end{tabular}

Esse favorecimento se repete quando se distinguem as modalidades oral e escrita, conforme se observa na tabela 3 .

TABELA 3

Experienciador por função sintática

\begin{tabular}{|c|c|c|c|c|}
\hline Modalidade Lingüística & \multicolumn{2}{|c|}{ Modalidade oral } & \multicolumn{2}{|c|}{ Modalidade Escrita } \\
\hline Função Sintática do & EXPS & EXPO & EXPS & EXPO \\
\hline \multicolumn{5}{|l|}{ Experienciador } \\
\hline Dados por Exp & 118 & 30 & 95 & 56 \\
\hline$\%$ & 79.7 & 20.3 & 62.9 & 37.1 \\
\hline Dados por modalidade & \multicolumn{2}{|c|}{148} & \multicolumn{2}{|c|}{151} \\
\hline TOTAL & \multicolumn{4}{|c|}{299} \\
\hline
\end{tabular}

De fato, ainda que o percentual de ExpS seja mais alto na modalidade oral $(79,7 \%)$, a modalidade escrita também privilegia enunciados na perspectiva do 
experienciador: $62.9 \%$ dos dados da modalidade escrita ilustram estruturas ExpS. Esses resultados se coadunam à definição geralmente obtida acerca dos verbos psicológicos: leigos e especialistas definem esses verbos como aqueles que denotam um estado psicológico e ilustram-nos sistematicamente através de exemplos que sempre se estruturam na perspectiva do experienciador, como, por exemplo, João desanima/se preocupa/ama.

\subsection{A relação entre a função sintática do experienciador e a realização morfológica do verbo}

A análise sintática dos verbos psicológicos revelou que os mesmos estruturamse preferencialmente com o experienciador na função sintática de sujeito. Paralelamente, a observação desses dados de uso revela um grande número de construções perifrásticas. Isto é, ao lado de construções como João (se) preocupa, ocorrem freqüentemente estruturas do tipo de João sente preocupação, João ficalé preocupado, todas permutáveis entre si. Uma análise das realizações morfológicas dos verbos detecta uma especialização entre essas e a função sintática do experienciador. As realizações morfológicas encontradas estão ilustradas abaixo com os verbos preocupar e/ou humilhar:

(5) ExpS $\sin$ (construção sintética com experienciador sujeito) Ex: Eu preocupo com o trabalho.

(6) ExpS pro (construção pronominal com experienciador sujeito) Ex: Eu me preocupo (se ergativo) com o trabalho.

(7) ExpS ana (construção analítica com experienciador sujeito) Ex.: Eu tenho/sinto preocupação / fico preocupado com o trabalho. ${ }^{5}$

(8) ExpO sin (construção sintética com experienciador objeto Ex.: O trabalho me preocupa.

(9) ExpO pro - (construção pronominal com experienciador objeto) Ex.: Ele se humilhou (se reflexivo).

(10) ExpO ana (construção analítica com experienciador objeto) Ex.: O trabalho causa preocupação em João.

A distribuição dessas propriedades pela função sintática do experienciador é demonstrada na tabela 4. 
TABELA 4

Realização morfológica dos verbos por função sintática do experienciador dentro de cada modalidade

\begin{tabular}{|c|c|c|c|c|}
\hline \multirow{2}{*}{$\begin{array}{c}\text { Modalidade } \\
\text { Função sintática } \\
\text { do experenciador }\end{array}$} & \multicolumn{2}{|c|}{ Modalidade oral } & \multicolumn{2}{|c|}{ Modalidade escrita } \\
\hline & EXPS & EXPO & EXPS & EXPO \\
\hline Realização SIN & 13 & 25 & 5 & 34 \\
\hline$\%$ & $11 \%$ & $83.3 \%$ & $5.3 \%$ & $60.7 \%$ \\
\hline Realização PRO & 23 & 1 & 28 & 17 \\
\hline$\%$ & $19 \%$ & $3.3 \%$ & $29.5 \%$ & $30.4 \%$ \\
\hline Realização ANA & 82 & 4 & 62 & 5 \\
\hline$\%$ & $70 \%$ & $13.3 \%$ & $65.3 \%$ & $8.9 \%$ \\
\hline Dados por Exp & 118 & 30 & 95 & 56 \\
\hline Dados por modalidade & \multicolumn{2}{|c|}{148} & \multicolumn{2}{|c|}{151} \\
\hline TOTAL & \multicolumn{4}{|c|}{299} \\
\hline
\end{tabular}

Os dados da tabela 4 demonstram que a forma analítica está a serviço da perspectiva do experienciador, enquanto a forma sintética se especializa no ponto de vista da causa: $70 \%$ (na modalidade oral) e $65.3 \%$ (na modalidade escrita) das realizações ExpS apresentam-se na forma analítica. Opostamente, quando a realização é de ExpO, $83.3 \%$ (na modalidade oral) e $60.7 \%$ (na modalidade escrita) dos enunciados apresentam o verbo na forma sintética.

Tendo em conta o comportamento idiossincrático dos verbos e a alta frequiência de alguns deles, avaliou-se que o perfil de alguns desses verbos poderia estar determinando o padrão (predomínio das estruturas ExpS) que emerge da análise global. No intuito de verificar essa possibilidade, observou-se o comportamento individual dos 23 verbos responsáveis pelas 299 ocorrências classificadas nas tabelas 3 e 4 . A distribuição dos verbos é apresentada em valores absolutos na tabela 5 . 
TABELA 5

Verbos por padrão sintático - modalidade oral e escrita

\begin{tabular}{|c|c|c|c|c|c|c|c|}
\hline \multirow{2}{*}{$\frac{\text { Modalidade }}{\text { Experienciador }}$} & \multicolumn{3}{|c|}{ Oral } & \multicolumn{3}{|c|}{ Escrita } & \multirow{2}{*}{$\begin{array}{c}\text { Total } \\
\text { Total ExpS } \\
\text { e ExpO }\end{array}$} \\
\hline & ExpS & ExpO & Total & ExpS & ExpO & Total & \\
\hline Acalmar & 0 & 0 & $\mathbf{0}$ & 6 & 12 & 18 & 18 \\
\hline Agradar & 0 & 6 & 6 & 0 & 3 & 3 & 9 \\
\hline Ameaçar & 0 & 1 & $\mathbf{1}$ & 2 & 4 & 6 & 7 \\
\hline Amedrontar & 26 & 3 & 29 & 18 & 2 & 20 & 49 \\
\hline Animar & 1 & 3 & 4 & 3 & 2 & 5 & 9 \\
\hline Apaixonar & 7 & 0 & 7 & 2 & 0 & 2 & 9 \\
\hline Apavorar & 5 & 0 & 5 & 1 & 1 & 2 & 7 \\
\hline Assustar & 4 & 1 & 5 & 3 & 3 & 6 & 11 \\
\hline Desanimar & 3 & 0 & 3 & 3 & 1 & 4 & 7 \\
\hline Desorientar & 1 & 1 & 2 & 3 & 2 & 5 & 7 \\
\hline Distrair & 4 & 2 & 6 & 2 & 8 & 10 & 16 \\
\hline Divertir & 6 & 0 & 6 & 6 & 0 & 6 & 12 \\
\hline Endoid(ar)(ecer) & 7 & 0 & 7 & 3 & 0 & 3 & 10 \\
\hline Enlouquecer & 3 & 0 & 3 & 5 & 0 & 5 & 8 \\
\hline Envergonhar & 5 & 0 & 5 & 4 & 1 & 5 & 10 \\
\hline Espantar & 1 & 0 & 1 & 9 & 1 & 10 & 11 \\
\hline Exaltar & 1 & 0 & $\mathbf{1}$ & 8 & 0 & 8 & 9 \\
\hline Humilhar & 0 & 3 & 3 & 1 & 3 & 4 & 7 \\
\hline Impressionar & 2 & 4 & 6 & 0 & 1 & $\mathbf{1}$ & 7 \\
\hline Incomodar & 0 & 3 & 3 & 3 & 5 & 8 & 11 \\
\hline Interessar & 12 & 2 & 14 & 0 & 1 & 1 & 15 \\
\hline Preocupar & 27 & 1 & 28 & 11 & 4 & 15 & 43 \\
\hline Tranqüilizar & 3 & 0 & 3 & 2 & 2 & 4 & 7 \\
\hline Total & 118 & 30 & 148 & 95 & 56 & 151 & 299 \\
\hline
\end{tabular}

A tabela 5 mostra o comportamento de cada um dos 23 verbos por padrão sintático. Observa-se que boa parte desses verbos apresenta um comportamento uniforme, quando se consideram as duas modalidades. Isto é, verbos como amedrontar, divertir, endoidar, preocupar privilegiam as estruturas ExpS tanto na modalidade oral quanto na modalidade escrita. Outros como humilhar, incomodar privilegiam as estruturas ExpO nas duas modalidades.

Esses dois grupos de verbos foram, então, analisados em relação a suas estruturas morfológicas quando realizam as estruturas ExpS e ExpO. O objetivo dessa análise foi o de verificar se o comportamento de cada item ilustra 
tendência à especialização, qual seja, a relação entre a perspectiva do enunciado e a realização morfológica.

TABELA 6

Estrutura morfológica dos verbos que privilegiam ExpS nas duas modalidades

\begin{tabular}{|c|c|c|c|c|c|c|c|}
\hline Experienciador & & ExpS & & & $\mathrm{pO}$ & & Total \\
\hline Formas & Sin & Pro & Ana & Sin & Pro & Ana & $\begin{array}{c}\text { Total ExpS } \\
\text { e ExpO }\end{array}$ \\
\hline Amedrontar & - & - & $89.8 \% *$ & - & - & $11.2 \%$ & 49 \\
\hline Apaixonar & - & $33.3 \%$ & $44.4 \%$ & - & - & $22.2 \%$ & 9 \\
\hline Desanimar & $42.9 \%$ & - & $42.9 \%$ & $14.3 \%$ & - & - & 7 \\
\hline Divertir & $8.3 \%$ & $91.7 \%$ & - & - & - & - & 12 \\
\hline Endoid(ar)(ecer) & $10 \%$ & - & $90 \%$ & - & - & - & 10 \\
\hline Enlouquecer & $50 \%$ & - & $50 \%$ & - & - & - & 8 \\
\hline Envergonhar & - & $10 \%$ & $80 \%$ & $10 \%$ & & & 10 \\
\hline Espantar & $9.1 \%$ & $27.3 \%$ & $54.5 \%$ & $9.1 \%$ & & & 11 \\
\hline Exaltar & & $88.9 \%$ & $11.1 \%$ & & & & 9 \\
\hline Preocupar & $7 \%$ & $27.9 \%$ & $53.5 \%$ & $11.6 \%$ & & & 43 \\
\hline
\end{tabular}

Como se vê na tabela 6, os verbos amedrontar, apaixonar, endoid(ar)(ecer), envergonhar, espantar e preocupar, que representam $60 \%$ dos dez verbos que favorecem as estruturas ExpS, realizam-se preferencialmente nas formas analíticas, conforme se ilustra de (11) a (17).

(11) (...) mas só de rapazes tinha medo. (p. 96 CL)

(12) (...) fiquei com medo dos cara tá lá. (I33)

(13) (...) ora dane-se, estava apaixonado. (p.51 FS)

(14) eu ficava doido que chegasse o Natal. (I38)

(15) ele tinha vergonha de ir lá. (I33)

(16) Carlota ficaria espantada. (p.43 CL)

(17) Nós temos muita preocupação...da...da linguagem...correta. (I23)

A análise do uso observado desses verbos (restrita, evidentemente, aos corpora sob análise) aponta para uma leitura preferencial dos mesmos. No caso de amedrontar, sua existência, como entrada lexical, é virtual, já que ele sempre se 
realiza através das formas perifrásticas, seja nas estruturas de $\operatorname{ExpS}$ (Ele tem medo), seja nas de ExpO (Isso dá medo).

Dos quatro verbos que não favorecem as formas analíticas, dois priorizam a forma pronominal (exaltar e divertir), e dois outros (enlouquecer e desanimar) dividem suas realizações entre a forma sintética (Ele enlouquece/desanima) e a forma analítica (Ele é/fica louco/desanimado.).

A Tabela 7 mostra a distribuição das formas entre os verbos que favorecem a perspectiva da causa, através das estruturas ExpO.

\section{TABELA 7}

Estrutura morfológica dos verbos que privilegiam ExpO nas duas modalidades

\begin{tabular}{|c|c|c|c|c|c|c|c|}
\hline \multirow{2}{*}{$\begin{array}{l}\text { Experienciador } \\
\text { Formas }\end{array}$} & \multicolumn{3}{|c|}{ ExpS } & \multicolumn{3}{|c|}{ ExpO } & \multirow{2}{*}{$\begin{array}{c}\text { Total } \\
\text { Total ExpS } \\
\text { e ExpO }\end{array}$} \\
\hline & Sin & Pro & Ana & Sin & Pro & Ana & \\
\hline Agradar & & & & $100 \%$ & 0 & 0 & 9 \\
\hline Ameaçar & & & & $71.4 \%$ & 0 & $28.6 \%$ & 7 \\
\hline Humilhar & & & & $71.4 \%$ & $14.3 \%$ & $14.3 \%$ & 7 \\
\hline Impressionar & & & $28.6 \%$ & $57.1 \%$ & 0 & $14.3 \% *$ & 7 \\
\hline Incomodar & & & & $72.7 \%$ & $27.3 \%$ & 0 & 11 \\
\hline
\end{tabular}

Conforme se observa na tabela 7 , os verbos que têm um comportamento coeso nas duas modalidades, no que diz respeito ao predomínio das estruturas ExpO, realizam essas estruturas através da forma sintética, preferencialmente, conforme se ilustra a seguir:

(18) Há outras coisas que podem nos humilhar mais... (p. 100 JA)

(19) (...) um pouso que me agrade. (p. $43 \mathrm{AD}$ )

(20) (...) igrejas que a meu ver não agradam. (I.32)

(21) (...) o que me impressionava quando era pequena. (I.24)

(22) (...) e também porque aquela beleza incomodava. (p. $47 \mathrm{CL}$ )

A tabela 8 apresenta tanto os verbos que não ocorreram nas duas modalidades como aqueles cujo predomínio de ExpS ou de ExpO nãoé uniforme nas duas modalidades. Também nesse subgrupo de verbos observa-se a tendência 
apontada nas tabelas 6 e 7, isto é, preferência para as formas analíticas nas estruturas ExpS, e para a forma sintética nas estruturas ExpO.

TABELA 8

Formas dos verbos com comportamento variável entre as duas modalidades

\begin{tabular}{l|ccccccc}
\hline Experienciador & \multicolumn{3}{|c}{ ExpS } & \multicolumn{3}{c}{ ExpO } & Total \\
\hline Formas & Sin & Pro & Ana & Sin & Pro & Ana & $\begin{array}{c}\text { Total ExpS } \\
\text { e ExpO }\end{array}$ \\
Acalmar & & & & & & & $\mathbf{1 8}$ \\
Animar & & & $33.3 \%$ & $5.6 \%$ & $\mathbf{6 1 . 1 \%}$ & & $\mathbf{9}$ \\
Apavorar & & & $\mathbf{4 4 . 4 \%}$ & $33.3 \%$ & $11.1 \%$ & $11.1 \%$ & $\mathbf{7}$ \\
Assustar & $14.3 \%$ & & $\mathbf{7 1 . 4 \%}$ & $14.3 \%$ & & & $\mathbf{1 1}$ \\
Desorientar & 36.4 & 27.3 & & 27.3 & & & $\mathbf{1 6}$ \\
Distrair & $14.4 \%$ & & $\mathbf{4 2 . 8 \%}$ & $\mathbf{4 2 . 8 \%}$ & & & $\mathbf{1 5}$ \\
Interessar & $12.5 \%$ & $12.5 \%$ & $12.5 \%$ & $\mathbf{3 1 . 3 \%}$ & $\mathbf{3 1 . 3} \%$ & 0 & $\mathbf{7}$ \\
Tranqüilizar & $6.7 \%$ & $33.3 \%$ & $\mathbf{4 6 . 7 \%}$ & 13.3 & & & \\
\hline
\end{tabular}

A constatação de que um número apreciável de verbos privilegia as formas analíticas para a perspectiva do experienciador e a forma sintética para a perspectiva da causa parece ilustrar a tendência das línguas naturais a estabelecer uma relação entre forma e sentido. Essa reflexão conduz à consideração da estrutura do léxico mental.

\section{A interação sintaxe-semântica e o papel do léxico}

\subsection{A construção das entradas lexicais}

Observadas as frequiências das estruturas morfológicas dos verbos e a relação entre essas e a função sintática do experienciador, pode-se propor que diversos verbos têm duas entradas, diferentemente do que fazem crer, às vezes, os dicionários da língua. ${ }^{6}$ Por exemplo, tendo em conta os verbos analisados na seção 3, pode-se propor que um verbo como tranqüilizar, que apresenta as realizações ExpS na forma analítica e as de ExpO na forma sintética, de forma categórica, nos corpora analisados, tem seu sentido de estar em estado de tranqüilidade associado às formas analíticas como estar/ficar tranqüilo e o sentido de causar tranqüilidade associado à forma sintética tranqüilizar. 
É possível que as frequiências das formas verbais sejam responsáveis por diferentes entradas lexicais, quando se pensa na configuração do léxico mental. Pode-se propor que os verbos que têm seus maiores percentuais de frequiências em ExpO na forma sintética são arquivados como causativos. ${ }^{7}$ Apesar de a freqüência dos dados ser relativa, isto é, limitar-se aos corpora sob análise, ${ }^{8}$ há que se considerar que esses dados podem estar ilustrando sua tendência geral na língua. De fato, verbos como agradar, ameaçar, humilhar, impressionar, incomodar, que tiveram seus maiores percentuais de ExpO realizados através da forma sintética (cf. tabela 7), parecem ter uma leitura preferencial como causativos. Isto é, o verbo é arquivado como ExpO, como leitura preferencial. Ao contrário, um verbo como enlouquecer, que apresentou realizações categóricas em ExpS e registrou 50\% das mesmas na forma sintética, tenderá a ter como leitura preferencial aquela cujo sentido é o de ficar louco e não o de causar loucura. Em alguns casos, a análise é um pouco mais complexa. Como a) os verbos que privilegiam ExpS o fazem preferencialmente através das formas analíticas; b) o arquivamento é feito pela forma, estabelece-se uma relação biunívoca, da seguinte maneira: uma forma é arquivada para um sentido ExpS, a outra forma acaba sendo selecionada para o outro sentido - ExpO, no caso. Assim, um verbo como amedrontar (que apresenta $89.8 \%$ de suas realizações ExpS na forma analítica, isto é ter/sentir medo é arquivado como tal - ter/sentir medo. A forma amedrontar acaba se especializando para a leitura causativa.

Com base nesse ponto de vista, é legítimo pensar que, quando se perguntar a um falante o sentido de amedrontar, sua resposta seja: causar medo. No caso de verbos como amedrontar, não há, a rigor, uma hierarquização de sentidos. O que há é o estabelecimento de uma especialização da função sintática do experienciador para cada sentido: ter medo é ExpS; amedrontar é ExpO. Já no caso de verbos como desanimar, em que a forma sintética realiza tanto estruturas ExpS (João desanima) como estruturas ExpO (Pedro desanima João), o arquivamento parece lidar com formas ambíguas, que se hierarquizam. No caso desses verbos, há uma leitura preferencial que é determinada pela frequiência das estruturas morfológicas de ExpS e de ExpO. Se a maior parte das realizações de ExpS de um verbo for na forma sintética, a leitura preferencial será a ergativa. É o que parece acontecer com o verbo desanimar, que, apesar de estar em processo de causativização, parece ter o sentido de sentir desânimo como leitura preferencial. Se, ao contrário, a maior parte das estruturas ExpS se 
realizar nas formas analíticas, a leitura preferencial do verbo será a causativa. Os verbos apavorar, interessar podem ilustrar esse tipo de leitura.

A presente análise qualitativa permite concluir que, já que as estruturas ExpS se realizam mais freqüentemente através das formas analíticas, a maior parte dos verbos ergativo-causativos tem sua leitura preferencial como causativos, quando considerados na forma sintética, isto é, em estado de dicionário. Eé como tais que esses verbos são analisados nas pesquisas que se orientam por dados intuitivos. Mas, como se viu, essa leitura preferencial deve ser analisada para cada verbo e é resultante de um entrecruzamento de três fatores, todos eles extraídos do uso: freqüência das estruturas ExpS, realização morfológica dessas estruturas, semelhança/diferença das realizações morfológicas de ExpO.

Da resolução dessa equação resultam três grupos:

a) com leitura preferencial ExpS: aqueles que privilegiam ExpS e a realizam também na forma sintética (desanimar, enlouquecer): eu desanimo/ enlouqueço eu fico desanimado/louco;

b) com leitura preferencial ExpO: que privilegiam ExpS apenas através das formas analíticas (endoidar, amedrontar): eu sou/fico doido, eu tenho medo/fico com medo;

c) com leitura preferencial ExpO: que privilegiam ExpO, seja através da forma analítica, seja através da forma simples (agradar, acalmar).

\subsection{Propriedades sintáticas e papéis temáticos}

Da leitura preferencial de cada verbo desses grupos resultam papéis temáticos complexos que determinam a possibilidade e aceitabilidade de propriedades sintáticas pouco comuns, como a passiva sintática, a causativa encabeçada e a de pro-arbitrário, incluídas entre os fatores da análise de Cançado (1995, 1996). Essa aceitabilidade forma um gradiente, de acordo com a elaboração desses papéis temáticos, cujos traços não serão tratados aqui. $\mathrm{O}$ fato é que os três grupos mencionados anteriormente são relacionáveis a essas propriedades da seguinte maneira: a aceitação de voz passiva, causativa encabeçada, e de proarbitrário parece ser categórica para os verbos do terceiro grupo, variável para os do segundo grupo e pouco provável para os do primeiro grupo. Há que se sublinhar, todavia, a dificuldade de se aferirem essas realizações, já que, como 
se viu, essas propriedades são praticamente virtuais nos dados de uso dos verbos psicológicos. A observação da frequiência de ocorrência de cada tipo de estrutura permite a postulação de dois grupos: o das propriedades nucleares e o das propriedades periféricas.

Como se viu na seção 3, a leitura preferencial de cada verbo está associada a propriedades nucleares que, por sua vez, parecem determinar a emergência de propriedades periféricas. No caso da presente análise, as propriedades nucleares são aquelas que se ilustram de (5) a (10), onde foram resumidas todas as estruturas encontradas para esses verbos. Portanto, essas propriedades são reais. Outras, como a passiva sintática (João foi humilhado por Pedro) a causativa encabeçada (Maria fez João humilhar Pedro), e a de pro-arbitrário (Humilharam João com aquela cena) são praticamente virtuais. Como se viu, nenhuma delas ocorreu nos dados analisados neste artigo. Vale lembrar que essas propriedades tampouco são identificadas quando se consideram os 2306 dados que guiaram a pesquisa relatada em Madureira (2000 e 2002). Diferentemente dessas, a de passiva adjetiva (do tipo de ficar preocupado) alcança índices de até $40 \%$ de realização, ao lado de outras estruturas estativas com os operadores ser e estar.

Constata-se, portanto, que análises intuitivas nivelam todas as propriedades, testando-lhes a gramaticalidade e/ou aceitabilidade para relacionálas a papéis temáticos específicos. Consideram-se simultaneamente propriedades nucleares (freqüentes, reais) e propriedades periféricas (pouco freqüentes ou apenas virtuais). É desse fato que decorre, certamente, a dificuldade de consenso quanto aos julgamentos de aceitabilidade das estruturas e, consequientemente, a dificuldade de estabelecimento de redes temáticas precisas, nas quais se encaixem os diferentes verbos, sem emergência de comportamentos idiossincráticos.

A presente análise propõe que os papéis temáticos constroem-se a partir das estruturas usuais mais freqüentes (reais, nucleares) de cada verbo. Os traços que os constituem determinam a possibilidade de emergência de outras propriedades (as periféricas). Trata-se de um processo aparentemente circular, que ganha dimensão dialética, quando se conjugam os pontos de vista sincrônico e diacrônico.

Uma questão decorre naturalmente do que se acabou de dizer: se os papéis temáticos se estabelecem com base em propriedades freqüentes, a que outros papéis essas propriedades nucleares correspondem? Além disso, de onde se 
extraem os mesmos? Deve haver uma resposta, caso contrário, será preciso admitir que algumas estruturas são primitivas na língua, e que, além disso, algumas só se explicam por princípios sintáticos. Ora, há de se convir que tal alternativa não convém a qualquer teoria que busque, de fato, compreender como se estrutura a linguagem: se há correspondência entre algumas propriedades e determinados papéis temáticos, isso deve ser verdadeiro para toda e qualquer propriedade.

A dificuldade de se estabelecerem papéis temáticos associados aos grupos de verbos que realizam preferencialmente algumas dessas propriedades nucleares reside no fato de os verbos apresentarem comportamentos idiossincráticos. Isto é, por que alguns verbos como desesperar, entristecer admitem a ergativa sem o pronome e outros como interessar não o fazem, ou, pelo menos, parecem menos aceitáveis, quando estruturados sem o pronome?

O cruzamento da presente análise com informações diacrônicas parece resolver a questão. Se recordarmos que, de acordo com Madureira (2000, 2002),

a) o grupo contemporâneo dos verbos ergativo-causativos compõe-se de verbos de distintas origens, entre os quais verbos como desesperar, primitivamente inacusativos;

b) ao se causativizarem, esses verbos não desenvolveram estruturas ambíguas,

somos obrigados a constatar que, apesar de desenvolver novos papéis temáticos (passando a admitir um papel causa) esses verbos mantiveram a possibilidade de estruturar enunciados na perspectiva do experienciador, pelo simples fato de o processo de causativização não ter gerado ambigüidade (ao contrário da causativização dos verbos originalmente acusativos, como, por exemplo, aborrecer). ${ }^{9}$

Assim, apesar de tornados estruturalmente iguais, esses verbos resistem a qualquer tentativa de agrupamento mediante princípios sintáticos ou semânticos. Não há papel temático ou qualquer parâmetro sintático que explique por que alguns verbos ergativo-causativos admitem a ergativa não pronominal e outros não a admitem. Aparentemente é possível dizer, então, que, na perspectiva sincrônica, a realização da ergativa sintética não se associa a qualquer papel temático específico, no que diz respeito a certos verbos, como desesperar, por exemplo. No caso desse verbo, essa estrutura é simplesmente manutenção de uma propriedade de outro período histórico e, portanto, associada a outra rede temática. E é como tal que esse verbo é marcado no léxico. 
Mas a manutenção de estrutura de outro período (associada, portanto, a outra rede temática) tem suas conseqüências. Se, contemporaneamente, um verbo ergativo-causativo realiza a ergativa sintética, também outros podem fazêlo. É precisamente isso que parece acontecer: verbos originalmente causativos, que já aderiram ao processo de ergativização e passaram a se estruturar com o pronome (tornado índice de promoção argumental), copiam as estruturas ergativas de verbos como desesperar, entristecer, cujo perfil histórico não ilustra estruturas com o pronome. Como se trata de dois processos que se cruzam, a variação fica ampliada: uns aderiram ao processo de causativização e precisaram marcar suas estruturas ergativas com pronome (aborrecer); outros não precisaram disso (desesperar). ${ }^{10}$

Esses últimos continuaram, de uma forma ou de outra, estruturando enunciados na perspectiva do experienciador. Tornados estruturalmente iguais aos originalmente causativos, desencadearam nesses últimos a propriedade de ergativização que alguns vão desenvolvendo (animar, preocupar), mas não todos (ameaçar, conquistar). Usado como elemento de desambiguação, o pronome caracterizou-se como marca de ergativização (junto com a preposição de que os verbos se fazem acompanhar), fixou-se na norma culta, de forma tal que passa a ser usado até nas estruturas originalmente inacusativas, determinando a variação João desespera e João se desespera.

Aí sim, está criado um novo padrão sintático que, todavia, está também em movimento, como se viu. Sua análise exige, portanto, que se observem o uso e a frequiência de cada uso, tomando, obrigatoriamente, como base de análise, o item lexical. Conforme se tentou demonstrar, as "etiquetas" que organizam o arquivamento dos itens escondem traços semânticos que determinam certas propriedades sintáticas, que, por sua vez, determinam novos traços semânticos e, assim, sucessivamente.

As estruturas realizadas pelos verbos psicológicos caracterizam-se, portanto, como resultado da atuação de fatores que se configuram no ponto de convergência de informações sintáticas e semânticas. Determinada pelo tempo/ espaço dos atos de linguagem, a configuração desses fatores é forçosamente relativa a cada verbo, por sua vez, devidamente inserido na história de seus usos. 


\section{Conclusão}

A pesquisa descrita neste artigo orientou-se pela reflexão acerca dos fatores que determinam que um falante desencadeie causativização ou ergativização para um verbo e não para o outro. Partiu-se da constatação de que o comportamento dos verbos psicológicos tomados em seu conjunto evidencia os dois processos. ${ }^{11}$ Levantaram-se questões acerca das razões pelas quais alguns verbos incluídos na subcategoria dos psicológicos ergativo-causativos fazem exceção a esses processos. Observou-se que essas questões vão ao encontro de outras, propostas por análises semânticas, que buscam explicar por que alguns verbos psicológicos admitem, por exemplo, a estrutura passiva, outros apenas a passiva adjetiva, e outros, as duas. ${ }^{12}$ Considerou-se que as análises semânticas ou sintáticas que lidam exclusivamente com dados intuitivos são insuficientes para dar conta do comportamento de cada verbo e propor generalizações, por mais que se refinem os princípios e parâmetros sintáticos ou os traços semânticos, dadas as reiteradas idiossincrasias dos verbos sob análise.

Apontou-se, então, que a solução parece estar numa abordagem que conjugue a análise do componente sintático à análise do componente semântico, através da consideração dos itens lexicais e da freqüência de seus tipos morfossintáticos. A análise quantitativa permitiu a) a identificação de propriedades sintáticas freqüentes, reais; b) o estabelecimento de relação entre essas propriedades e tipos morfossintáticos; c) a determinação das propriedades menos freqüentes pelos fatos apresentados em a e e $\underline{\mathrm{b}}$ e pelos traços semânticos que daí decorrem, em parte.

A análise qualitativa concluiu que a) o estabelecimento dos traços semânticos dos verbos submete-se aos tipos morfológicos através dos quais os verbos realizam as propriedades mais freqüentes; b) a variação de tipo morfológico determina duas entradas lexicais para um mesmo verbo, ou entradas ambíguas, com uma leitura preferencial. Por fim, sugeriu-se que a atribuição de propriedades sintáticas e de traços semânticos resulta de fatores de duas ordens, quais sejam, os da estrutura, observáveis através de uma consideração da freqüência na perspectiva sincrônica, e os do item lexical, observáveis através da análise do percurso histórico de cada verbo. 


\section{Abreviaturas referentes aos corpora}
$\mathrm{AD} \quad$ - $\quad$ Autran Dourado (Ópera dos mortos)
C - Clarice Lispector (Laços de família)
FS - Fernando Sabino (A mulher do vizinho)
I. - Informante
JA - Jorge Andrade (A moratória)

\section{Notas}

${ }^{1}$ A primeira versão deste relato de pesquisa foi apresentada em Dogliani, 2003(a). ${ }^{2}$ Isto é, o papel temático que expressa aquele que experiencia o sentimento /a emoção.

${ }^{3}$ Reflexões mais detalhadas sobre essa propriedade encontram-se em WhitakerFranchi (1989) e Cançado (1995, 1996).

${ }^{4}$ Os dados analisados neste artigo não distinguem as regiões.

${ }^{5}$ Apesar de as formas do tipo ficar preocupado serem destacadas na literatura relevante, como ilustrativas da propriedade chamada passiva adjetiva, por oposição à passiva propriamente dita, essa construção não foi distinguida de outras estruturas analíticas, tendo em vista as conclusões de Madureira (2000), segundo as quais se trata de uma propriedade freqüente que não pode ser oposta à passiva propriamente dita, propriedade praticamente ausente do conjunto de dados.

${ }^{6}$ Bybee (2001) postula o mesmo, no nível das representações fonológicas.

${ }^{7}$ Não se está defendendo a idéia de que as frequiências ilustradas nos corpora em análise correspondem às freqüências dos mesmos verbos na língua. Para tanto, será necessário o estabelecimento de comparação com corpora externos. A presente abordagem lida, além disso, com a pressuposição de que o uso dos diferentes tipos morfossintáticos varia de indivíduo para indivíduo, de acordo com as redes sociais que cada um integra.

${ }^{8}$ A avaliação da frequiência é relativa na presente análise já que se limita a dois corpora. Como se vê na discussão apresentada no texto, o perfil evidenciado pelos verbos parece coadunar-se com o perfil real que alguns deles exibem na língua. A confirmação da frequiência absoluta requer a comparação com os dados de outros corpora, trabalho que está em preparo.

${ }^{9} \mathrm{Cf}$., a esse respeito, Madureira, 2002. 
${ }^{10}$ De acordo com Dogliani (2003b), uma observação do comportamento desses verbos no francês permite sustentar essa análise: o processo de causativização não caracteriza esse grupo de verbos. Além disso, as construções ergativas não ilustram a variação observável no português.

${ }^{11} \mathrm{O}$ refinamento de papéis temáticos não dá conta desses casos, conforme foi demonstrado em Madureira, 2000.

${ }^{12} \mathrm{Cf}$., a esse respeito, Cançado, 1996.

\section{Referências Bibliográficas}

BELLETTI, A.; RIZZI, L. Psych verbs and theta-theory. Natural language and linguistic theory, n. 6, p. 291-352, 1988.

BITTENCOURT, V. Da expressão da causatividade no português do Brasil: uma viagem no túnel do tempo. 1995. Tese (Doutorado em Lingüística) - PUC, São Paulo.

BURZIO. L. Italian syntax. Dordrecht: D. Reidel, 1986.

BYBEE, J. L. Phonology and language use. Cambridge: University Press, 2001.

CANÇADO, M. Verbos psicológicos: a relevância dos papéis temáticos vistos sob a ótica de uma Semântica Representacional. 1995. Tese (Doutorado em Lingüística) - IEL, UNICAMP, Campinas.

CANÇADO, M. Análise descritiva dos verbos psicológicos do português brasileiro. Revista de Estudos da Linguagem, Belo Horizonte, Faculdade de Letras da UFMG, v. 5, p. 89-114, 1996.

DOGLIANI, Evelyne. Relação sintaxe-semântica: uso e freqüência dos itens lexicais. Comunicação apresentada durante o III Congresso Internacional da Abralin, UFRJ - Rio de Janeiro, 13-15 de março de 2003 (a).

DOGLIANI, Evelyne. Constructions ergatives des verbes psychologiques: une comparaison entre le portugais et le français. 2003(b). (Inédito)

MADUREIRA, Evelyne Dogliani. Difusão Lexical e mudanças sintático-semânticas:os verbos psicológicos. 2000. Tese (Doutorado em Estudos Lingüísticos) - Faculdade de Letras, Universidade Federal de Minas Gerais, Belo Horizonte.

MADUREIRA, Evelyne Dogliani. Variação nas construções pronominais dos verbos psicológicos:uma decorrência de diferentes percursos históricos. In: COHEN, M. A.; RAMOS , J. (Org.). Dialeto mineiro e outras falas - estudos de variação e mudança lingüística. Belo Horizonte: Faculdade de Letras/UFMG, 2002. 
PERLMUTTER, David. Impersonal passives and the unaccusative hypothesis. ANNUAL MEETING OF THE BERKELEY LINGUISTIC SOCIETY, 4. Proceedings... Berkeley, UCLA, 1978

TARALLO, F. Diagnosticando uma gramática brasileira. In: KATO, M.; ROBERTS, I. (Ed). Português Brasileiro: uma viagem diacrônica. Campinas, São Paulo: Ed. da UNICAMP, 1993. p.69-105 .

WHITAKER-FRANCHI, R. C. As construções ergativas: um estudo semântico e sintático. 1989. Dissertação (Mestrado) - IEL, UNICAMP, Campinas. 